\title{
Sobre Dramaturgia da Dança
}

\author{
Guy Cools ${ }^{1}$ \\ Fontys School of Fine and Performing Arts, Tilburg, Netherlands \\ E-mail: gjhcools@yahoo.ca \\ Tradução de Fellipe Resende \\ Universidade Federal do Rio Grande do Sul, Porto Alegre, Brasil \\ E-mail: fellipe.resende@gmail.com
}

Resumo

Em 1994, Marianne Van Kerkhoven, a madrinha flamenga da dramaturgia da dança, escreveu um pequeno artigo seminal sobre o assunto - Looking without pencil in the hand - do qual o título por si só já é um manifesto. Essa contribuição se desenvolve ainda mais nos insights de Van Kerkhoven: como o dramaturgo deve permanecer necessariamente invisível no processo criativo que ele(a) está apoiando; como, de modo a capturar esse papel invisível, muitas metáforas foram criadas. $O$ texto continua com olhares para os diferentes papéis que assumo em minha própria prática: a de testemunha somática, parceiro de diálogo e editor. Ele conclui-se reafirmando a prática do dramaturgo (de dança) como uma prática criativa na qual todo o corpo está envolvido e na qual a proximidade somática do processo criativo é tão importante quanto a distância crítica.

\section{Palavras-chave}

Dramaturgia da dança. Testemunha somática. Parceiro de diálogo. Editor.
Abstract

In 1994, Marianne Van Kerkhoven, the Flemish godmother of dance dramaturgy wrote a short, seminal article on the subject - Looking without pencil in the hand - of which the title alone is already a manifesto. This contribution builds further on Van Kerkhoven insights': how the dramaturge has to stay necessarily invisible in the creative process (s)he is supporting; how in order to capture this invisible role, a lot of metaphors have been created.

It continues with looking at the different roles I take up in my own practice: that of somatic witness, dialogue partner and editor. It concludes reasserting the practice of the (dance) dramaturge as a creative practice in which the whole body is involved and in which somatic proximity to the creative process is as important as critical distance.

Keywords

Dance Dramaturgy. Somatic Witness.

Dialogue Partner. Editor. 
A dramaturgia da dança é uma disciplina e profissão relativamente jovem. O primeiro dramaturgo de dança oficial na Europa foi Raimund Hoghe, o qual foi creditado nessa função com Pina Bausch em 1979. Logo depois, outras figuras icônicas da primeira geração se seguiram, tais como Marianne Van Kerkhoven com Anne Teresa De Keersmaeker ou Heidi Gilpin com William Forsythe.

Uma influente definição de dramaturgia a define como a organização das ações da performance, o 'entrelaçamento' dos diferentes e frequentemente multidisciplinares segmentos do trabalho. Entende-se que o pensamento e as estratégias dramatúrgicas contribuem para a qualidade do trabalho, sua legibilidade e acessibilidade.

Como na maioria das vezes não há texto ou roteiro dos quais partir, a dramaturgia da dança, que é frequentemente definida como "dramaturgia aberta", é muito mais orientada pelo processo e baseia-se em habilidades dialógicas e na capacidade de estimular a dinâmica e o intercâmbio de grupos. Marianne Van Kerkhoven, considerada mundialmente como uma das madrinhas da profissão, definiu-a da seguinte forma:

O tipo de dramaturgia a que me refiro, e que tento aplicar tanto no teatro quanto na dança, segue um certo 'processo':

\footnotetext{
1 Dr. Guy Cools é um dramaturgo de dança. Atribuições recentes incluem Professor Associado de Pesquisa no instituto de pesquisa Artes na Sociedade da Fontys Escola de Artes Visuais e Cênicas em Tilburg, e Pesquisador de Pós-Doutorado na Universidade de Ghent, onde concluiu seu doutorado guiado pela prática (practice-based $P h D$ ), na relação entre dança e escrita. Trabalhou como crítico de dança e curador de dança. Atualmente, dedica-se à dramaturgia de produção, contribuindo para o trabalho de coreógrafos de toda a Europa e Canadá. Suas publicações mais recentes incluem The Ethics of Art: ecological turns in the performing arts, co-editadas com Pascal Gielen (VALIZ, 2014); In-between Dance Cultures: on the migratory artistic identity of Sidi Larbi Cherkaoui and Akram Khan (VALIZ, 2015) e Imaginative Bodies, dialogues in performance practices (VALIZ, 2016). Com o coreógrafo canadense Lin Snelling, ele desenvolveu uma prática de performance improvisada 'Rewriting Distance' (veja também: www.rewritingdistance.com), focada na integração de movimento, voz e escrita. Cools mora em Viena (Áustria).
}

escolhemos conscientemente material de várias origens (textos, movimentos, imagens de filmes, objetos, ideias, ...); o 'material humano' (atores / bailarinos) prevalece claramente sobre o resto; as personalidades dos artistas e não suas capacidades técnicas são a base da criação. O diretor ou coreógrafo começa com esses materiais: no decorrer do processo de ensaio, ele/ela observa como os materiais se comportam e se desenvolvem; somente no final de todo esse processo é que gradualmente distinguimos um conceito, uma estrutura, uma forma mais ou menos claramente delineada; essa estrutura não é de forma alguma conhecida no início. (KERKHOVEN, 1997, pp. 20-21).

Em um nível superior de organização, a reflexão dramatúrgica também é uma meta-reflexão sobre o desenvolvimento da carreira do artista, o processo criativo e suas metodologias, os processos de colaboração interdisciplinar, o papel e a função dos artistas/organizações na sociedade e o relacionamento que $\mathrm{o}$ artista quer estabelecer com a mesma.

Em outro de seus ensaios seminais, Of micro and macro dramaturgy (1999), Marianne Van Kerkhoven definiu micro dramaturgia como 'a dramaturgia que se situa em torno de uma produção concreta'; enquanto a macro dramaturgia lida com 'a relevância social e a função do teatro'. Para Van Kerkhoven, o dramaturgo sempre tenta construir pontes entre a micro e a macro dramaturgia e, como tal, apoia os artistas em sua tentativa de "nos ajudar a ler o mundo e decifrar suas complexidades'.

\section{- O dramaturgo precisa permanecer invisível}

Um pequeno ensaio anterior, Looking without pencil in the hand (1994), publicado por Marianne Van Kerkhoven na edição temática On Dramaturgy da Theaterschrift (de cuja série ela era editora), permanece 
até hoje o principal ponto de referência para muitas outras publicações recentes. Isso ocorre tanto por seu conteúdo despretensioso e honesto quanto por sua forma poética. Em 12 breves declarações axiomáticas, enquadradas entre duas citações de Susan Sontag e Paul Valéry (de quem se deriva o título da última declaração), ela captura todas as atitudes e qualidades essenciais - artística e éticamente - pelas quais um dramaturgo deve trabalhar e viver. Por exemplo:

9. Dramaturgia é uma profissão limitada. O dramaturgo deve ser capaz de lidar com a solidão; ele/ela não tem residência fixa, ele/ela não pertence a lugar algum. $O$ trabalho que ele faz dissolve na produção, se torna invisível. Ele/ela sempre compartilha as frustrações e ainda não precisa aparecer na foto. O dramaturgo não é (talvez: não exatamente ou ainda não) um artista. Qualquer um que não possa, ou não consiga mais lidar com esse aspecto de servir -ainda que criativo -, é melhor fora disso. (KERKHOVEN, 1994, p. 144).

Sua declaração sobre a necessária invisibilidade do dramaturgo foi escolhida e desenvolvida por Cindy Brizelli e André Lepecki em sua introdução à edição especial de dramaturgia de 2003 da revista feminista Women and Performance, intitulada The labor of the question is the (feminist) question of dramaturgy: "Trabalho invisível, então, manchado com ressonâncias míticas. Para o dramaturgo se ladear não apenas com o trabalho manual das mulheres, mas também com uma certa fantasia materna - o dramaturgo resolve problemas, suaviza a psicose da produção e, mediante solicitação, deve sempre ser capaz de fornecer a resposta certa." (LEPECKI, 2003, p. 15). Mesmo em uma edição temática muito mais recente de um periódico, sobre Dance and Movement Dramaturgy (2013) pela Canadian Theatre Review, os escritores continuam referen- ciando o ensaio de Van Kerkhoven e discutindo a 'figura camaleônica' do dramaturgo (MONTAIGNAC, 2003, p. 10), ou, como Jacob Zimmer resume em seu estilo mais irônico: "A definição constante da dramaturgia é a piada das conferências e também a força do campo. A reflexão constante e as formulações profundamente pessoais são a característica, não a falha." (ZIMMER, 2003, p. 17).

A inevitável invisibilidade da contribuição do dramaturgo para o trabalho final muitas vezes levou a uma mistificação de seu papel no processo criativo. Isso resultou em uma riqueza de imagens e tentativas de encontrar uma linguagem metafórica para tentar capturar e definir a natureza desse papel. As metáforas usadas para o dramaturgo incluem o muito estabelecido, mas problemático, 'olho de fora', ou a mais poética, 'acumulador, coletando tudo o que brilhou' (RADOSAVLJECIC, 2009, p.46), uma 'enorme mochila de bits de informação úteis e não úteis' (KERKHOVEN), 'portador da bússola' (TURNER; BEHRNDT; RADOSAVLJECIC, 2009, p. 50). Entre as metáforas que eu prefiro estão:

\section{Parteira}

Um dramaturgo é como uma parteira. Você apoia o processo que acontecerá de qualquer maneira, mesmo sem a sua presença. Você usa sua experiência prévia de processos semelhantes para orientar os 'pais / artistas' e noventa por cento do tempo apenas assegura a eles que tudo está acontecendo como deveria. E mesmo nos dez por cento de tempo em que você interfere, você aprende a ser paciente e a aguardar porque sabe que quanto mais natural o nascimento, mais contentamento haverá. A metáfora da parteira também ressoa com a noção de parteira Socrática que apoia o surgimento de novas ideias. 


\section{Auxiliar de cozinha}

Como estudante, trabalhei muito em cozinhas de restaurantes e, desde então, comparei com frequência a arte da coreografia à arte de cozinhar - para usar a mesma metáfora que George Balanchine usou. É uma questão de escolher os ingredientes/pessoas certos e, em seguida, é uma questão de encontrar a ordem e o ritmo certos, para que os gostos/talentos individuais se reforcem, em vez de enfraquecerem-se. Como dramaturgo, sinto-me privilegiado por ter trabalhado nas cozinhas de grandes chefs e minha principal contribuição tem sido muitas vezes repassar receitas de um para o outro. Compartilho essa metáfora com Marianne Van Kerkhoven que, no parágrafo de abertura de Looking with pencil in the hand, afirma que o "pedido para conversar ou escrever sobre seu trabalho leva a um sentimento de constrangimento, semelhante ao sentimento de ser solicitada a revelar alguém segredos ou receitas culinárias de outra pessoa" (KERKHOVEN, 1994, p. 140).

\section{Corpo Externo}

Eu sou mais do que apenas meus olhos. Seguindo um argumento originalmente apresentado por André Lepecki, Myriam Van Imschoot (2003) afirma que a noção de 'olho de fora' separa a dramaturgia do corpo do artista.

"Lepecki resiste à idéia do dramaturgo (o olho) como o lugar do poder e do conhecimento, colocado à disposição de um coreógrafo, que (se estendermos a metáfora) é percebido como sendo inteiramente corpo - um corpo cego e mudo, esperando ser iluminado pela visão e pela fala." (IMSCHOOT, 2003, p. 63).

Por isso, prefiro o termo 'corpo externo'. Eu o usei pela primeira vez na brochura do programa da R.A.F.T. (2005), um projeto de improvisação realizado por Marc Boivin em Montreal, para o qual me pediram para ser o dramaturgo. Eu estava presente em todos os ensaios e na primeira série de apresentações públicas e senti que meu corpo externo e silencioso era parte integral do show. Christel Stalpaert aprofundou ainda mais essa noção de 'corpo externo' em sua visão de uma dramaturgia corporal (STALPAERT, 2009, 2014).

Essencialmente, a questão da definição do trabalho do dramaturgo remonta à dicotomia tradicional de processo e produto. A dramaturgia é uma qualidade do resultado final, da performance, ou é uma atitude que acompanha o processo criativo, o devir do trabalho? As definições tradicionais de dramaturgia favorecem a primeira, como por exemploadefiniçãoclássicadeEugenioBarba:

A palavra texto, antes de se referir a um
texto escrito ou falado, impresso ou ma-
nuscrito, significava 'um entrelaçamento'.
Nesse sentido, não há performance que
não tenha 'texto'. Aquilo que diz respeito
ao texto (a trama) da performance pode
ser definido como 'dramaturgia', isto é,
drama-ergon', o 'trabalho das ações'
na performance. (BARBA, 1991, p. 68).

A natureza mais orientada pelo processo da dramaturgia da dança também a leva a ser descrita como o próprio movimento. Já em um ensaio inicial sobre dramaturgia da dança, Jean Marc Adolphe definiu a dramaturgia da dança como "um exercício em circulação" (ADOLPHE, 1997, p. 33). A dramaturgia como movimento também é o tema recorrente na edição especial da Performance Research, On Dramaturgy (2009), que foi uma continuação da conferência internacional European Dramaturgy in the 21st Century, realizada em Frankfurt em 2007. Em sua auto-reflexão sobre seu trabalho como dramaturga no Reino Unido, The Need to Keep Moving, Duska Radosavljevic define-se

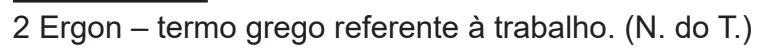


com referências a The Practice of Everyday Life, de De Certeau, como 'um corpo (móvel) no ambiente de produção teatral' (RADOSAVLJECIC, 2009, p. 45) cuja 'condição cigana' (Id, p. 50) e o 'estar à margem, literal e metaforicamente' permitem 'construção de pontes' e "uma negociação entre fronteiras entre teoria e prática, entre escritores e diretores, entre o espetáculo e o público, entre o teatro e a academia e, às vezes, entre diferentes culturas também." (Id, p. 48).

Para muitos, esse movimento necessário do dramaturgo é um movimento entre proximidade e distância. Maaike Bleeker invoca a discussão de Deleuze e Guatttari sobre amizade em What is philosophy? (1994), quando ela descreve a relação entre dramaturgo e coreógrafo como o momento que inicia 'pensamentos que se movem'. Essa relação entre dramaturgo e coreógrafo é ela própria "um movimento que envolve proximidade e distância, similaridade e diferença" (BLEEKER, 2003, p. 163). A mesma referência à noção de amizade de Deleuze é retomada por Bettina Masuch (2009, p. 137), ao discutir seu relacionamento com Meg Stuart. Bojana Cvejic também invoca a figura do "amigo a fim de acabar com a instrumentalidade e especialização do papel e da relação do dramaturgo com o coreógrafo" (CVEJIC, 2009, p. 25). E Jacob Zimmer (2009) intitula sua contribuição para a edição temática da Canadian Theatre Review 'Friendship is no day job and other thoughts of a resident dance dramaturg' (ZIMMER, 2013, p. 16).

Bojana Kunst finalmente coloca a 'flexibilidade' do dramaturgo para se deslocar entre as posições e sua 'proximidade afetiva' do processo criativo dentro do atual discurso pós-fordiano sócio-econômico de mudanças de produção e trabalho:

Uma das principais razões para a entrada da dramaturgia na dança pode ser encontrada nos contextos em mudança da prática artística e do trabalho social. A entrada do dramaturgo na dança pode ser lida como conseqüência das mudanças na economia política do trabalho, onde a produção da linguagem, dos contextos e das habilidades humanas cognitivas e afetivas é levada ao primeiro plano. (...) É por isso que o trabalho do dramaturgo é fortemente caracterizado pela flexibilidade: como participante do processo, o dramaturgo pode ocupar uma variedade de papéis - os de dramaturgo prático, produtor, diretor do festival, gerente de palco, escritor, jornalista, professor, líder de oficina, coach, palestrante, acadêmico, artista, bailarino, membro da rede de produção, orientador de política cultural, mentor, amigo, bússola, memória, companheiro de viagem, mediador, psicólogo. (KUNST, 2009, pp.85-86).

Eu próprio ocupei todos os papéis mencionados acima, mas em meu próprio processo contínuo de tentar me situar, defino hoje a dramaturgia como a reflexão crítica do artista sobre o porquê e o como desenvolver a linguagem e o processo criativo de alguém. Meu interesse e foco mudaram de dar suporte a criação de uma produção específica para o desenvolvimento de uma linguagem artística específica, e de lá para o processo criativo como tal. Se eu puder oferecer aos artistas ferramentas para transformar e melhorar seu processo criativo, certamente a linguagem e o trabalho resultante dele também evoluirão.

\section{O dramaturgo como testemunha, parceiro de diálogo e editor}

Embora o corpus de texto sobre dramaturgia da dança tenha começado recentemente a crescer de forma substancial, ainda há muito pouca literatura que descreva o trabalho real que um dramaturgo faz no processo criativo. Dramaturgy in the Making (2015) de Katalin Trencsényi é uma das poucas exceções. André Lepecki, discutindo sua colaboração com Meg Stuart, lista uma 
série de tarefas que vão de 'ler todos os livros sugeridos pelo coreógrafo' a 'lembrar de algo que aconteceu meses antes, que havia sido descartado e agora era necessário novamente' (LEPECKI, 2009 66-67).

A visão geral que Liesbeth Wildschut dá em Reinforcement for the choreographer: The dance dramaturge as ally, o capítulo sobre dramaturgia da dança na Contemporary Choreography. A cricitical Reader (2009), discrimina uma longa lista de perguntas que o dramaturgo deve fazer em diferentes estágios do processo. Mas a série de verbos que acompanha essas perguntas - refletir, comentar, analisar, interpreter,...indica que ela continua a situar a contribuição do dramaturgo principalmente dentro do domínio racional e analítico de adicionar 'significado' e 'coerência'.

Quem mais se aproxima da maneira como descrevo minha própria prática como dramaturgo é Katia Montaignac, que distingue três funções diferentes: a de testemunha, parceiro de discussão e pesquisador (MONTAIGNAC, 2013, p. 11). Embora a última também seja uma tarefa possível, não a considero uma parte específica do processo criativo ou exclusiva do dramaturgo. Os três papéis que eu descreveria como essenciais para o trabalho do dramaturgo são: a testemunha (silenciosa), o parceiro ou moderador do diálogo e o editor.

\section{O dramaturgo da dança como tes-} temunha somática

(...) o artista Chris Burden descreveu aqueles que o observavam naquela noite não como audiência ou espectadores, mas como testemunhas.É uma distinção a que volto repetidas vezes e uma a que a performance contemporânea se liga incessantemente porque testemunhar um evento é estar presente de alguma maneira fundamentalmente ética, sentir o peso das coisas e o lugar próprio nelas, mesmo que esse lugar seja simplesmente, por enquanto, como espectador. (ETCHELLS, 1999, p. 17).

De maneira semelhante a Tim Etchells na citação acima, Ann Cooper Albright descreve (na introdução de seu livro, Choreographing Difference: The Body and Identity in Contemporary Dance (1997) como assistir a performance La Tristeza Complice de Les Ballets $C$ de la B/Alain Platel transformou seu 'ato de assistir no ato de testemunhar'.

Testemunhar algo implica uma capacidade de resposta, a resposta/habilidade do espectador em relação ao artista. É radicalmente diferente do que poderíamos chamar de olhar 'consumidor' que diz 'aqui, você me entretém, eu comprei um ingresso, e vou sentar e assistir'. (...) Por outro lado, o que chamo de testemunhar é muito mais interativo, um tipo de percepção (com todo o corpo) comprometida com um processo de diálogo mútuo. (ALBRIGHT, 1997, p. xxii).

Trazer o papel de testemunha para o estúdio, o mais cedo possível no processo de criação, é uma das coisas mais poderosas que você pode contribuir como dramaturgo. Já através de sua presença silenciosa, mas sentida, você influenciará somática e energicamente o diálogo entre coreógrafo e intérpretes e entre os próprios intérpretes.

Muito pouca literatura sobre dramaturgia da dança fala sobre esse potencial somático e energético do papel de testemunha. Christel Stalpaert menciona a dramaturga Carmen Menhert descrevendo seu trabaIho como um 'diálogo em nível de energia' (STALPAERT, 2009, p. 123) e Eleonora Fabião discute isso de forma mais explícita em sua contribuição para a edição On Dramaturgy of Women and Performance:

Eu poderia explorar uma qualidade de interação que me interessa muito, um tipo de 'comunicação energética'. Pode parecer abstrato, mas esse modo de agir sobre alguém é tão concreto quan- 
to eficaz. Como alguns entendimentos só podem ser formulados através de uma boa conversa, outros só podem ser produzidos por esse tipo de intercâmbio, através da interseção de energia e conversas silenciosas. Você pode energizar e ser energizado (ou estimular e ser estimulado) se concentrar sua atenção. Atores e diretores são particularmente treinados para resolver as coisas dessa maneira. E, como eu entendi, os dramaturgos também podem se beneficiar muito dessa estratégia de comunicação. Se uma das especificidades mais interessantes da cena teatral é a qualidade magnética das presenças, a importância de investigar e gerar meios energéticos de comunicação parece óbvia. (FABIÃO, 2003, p.30)

Para mim, o papel de testemunha é uma parte essencial e criativa do meu trabalho como dramaturgo. O jogo intuitivo com a proximidade ou a distância em relação ao processo existe principalmente para criar mudanças sutis no papel de testemunha que podem influenciar a interação basal entre artistas e/ou coreógrafo. Nos estágios iniciais de um processo de ensaio, eu também gosto de participar e experimentar fisicamente a pesquisa física em meu próprio corpo. É também uma maneira de fazer com que a distância em relação ao material e as pessoas seja tão íntima quanto as pessoas. Quando, nas fases posteriores, eu constantemente saio e me reinsiro o processo, minha presença ou ausência sentida também muda energicamente o espaço compartiIhado e nossa 'relacionalidade' e, ao fazê-lo, isso influencia sutilmente o processo.

\section{- A dramaturgia da dança como prá- tica dialógica}

Previamente, antes dos ensaios, o trabalho mais importante acontece: conversas que esclarecem as perguntas e curiosidades que levam à criação de uma peça. Falamos sobre como trabaIhar, como criar vocabulário, estrutura e significado. Falamos sobre onde trabaIhar, já que diferentes espaços de ensaio produzem espetáculos diferentes. Falamos sobre quando trabalhar, pois horários diferentes produzem espetáculos diferentes. Falamos sobre o que fazer no ensaio - que tipo de preparação, o quanto de falar, o quanto de fazer: deve haver visitas de campo, improvisação? (ZIMMER, 2013, p. 17).

Maaike Bleeker vê no diálogo o momento em que a reflexão dramatúrgica da qual o coreógrafo também é capaz, se exterioriza em outra pessoa, o dramaturgo (BLEEKER, 2003, p. 166). O dramaturgo André Lepecki, em sua colaboração com Meg Stuart, define essa prática dialógica como um 'ato de tradução' de "Meg para os bailarinos; dos bailarinos para os bailarinos; de Meg para Meg; dos bailarinos para Meg; de mim mesmo para Meg; de mim para os bailarinos; e dá forma a tudo isso para todos os outros colaboradores." (LEPECKI, 2010, p. 66). Em sua enumeração de atividades dramatúrgicas, esta é apenas uma de muitas. Para a própria Meg Stuart, no entanto, é a essência da colaboração deles: "Um processo dramatúrgico começa com um diálogo com alguém em quem você confia. (...) Eles também são um grande ouvido com quem compartilho minhas perguntas iniciais e depois minhas dúvidas, para não espalhá-las por todo o estúdio." (STUART, 2010, p.134).

Da mesma forma que Jacob Zimmer descreve a importância da conversa antes do início do processo de ensaio, meu trabaIho como dramaturgo acontece tanto fora do estúdio quanto dentro. Enquanto dentro do estúdio o papel de testemunha é o mais dominante, fora dele eu me encontro regularmente com o coreógrafo (em qualquer lugar, diária ou semanalmente, dependendo das necessidades do processo) para discutir o que está acontecendo no estúdio. Idealmente, essas conversas começam o mais cedo 
possível, quando as primeiras ideias para uma nova criação germinam (às vezes ainda enquanto se trabalha na peça anterior) e se intensificam durante o curso do processo de ensaio. Da mesma forma como descrevi anteriormente que meu foco mudou do resultado final para o processo criativo, essas discussões não se concentram tanto no material que é desenvolvido, mas no que é necessário para alimentar ainda mais o processo: por exemplo, na comunicação com os artistas; que tipo de input eles precisam; qual a melhor forma de planejar e organizar o horário dos ensaios; como começar a pensar em uma maneira possível de organizar o material paralelo ao seu desenvolvimento.

A hora e o local dessas conversas são cruciais e mudam a cada coreógrafo e/ou produção. Sua forma também requer alguma reflexão. Várias vezes isso aconteceu, por exemplo, escrevendo cartas e atualmente é feito à distância com frequência pelo Skype ou FaceTime.

Assim sendo, a conversa é muito diferente do chamado feedback. É muito mais aberta e sem propósito. Os únicos tipos de feedback que parecem relevantes e úteis nessa conversa em particular são lembretes de ideias e conversas anteriores, que servem para se reconectar com a jornada em que se estabeleceram juntos. Acredito muito na noção de que no processo criativo 'as primeiras idéias são sempre as corretas'. Assim o feedback geralmente existe apenas para lembrar o coreógrafo dessas linhas de vida iniciais e mais vitais do trabalho.

\section{O dramaturgo da dança como editor}

"Uma das obrigações do editor é levar, como um cálice sagrado, o foco da atenção do público e movê-lo de maneiras interessantes pela superfície da tela." (MURCH; ONDAATJE, 2002, p. 277)

Quando li pela primeira vez o livro The Conversations, de Walter Murch and the Art of Editing Film, de Michael Ondaatje (2002), imediatamente me reconheci como um dramaturgo de produção no papel de editor de filmes. Na forma de dramaturgia aberta que eu pratico, o processo de edição acontece na sala de ensaio, onde, através de acidentes e mudanças no processo, o material revela por si só como está meIhor conectado. Muitas vezes, é apenas uma questão de estar atento, reconhecendo os momentos e agindo sobre eles.

Uma função principal do processo de edição é manter o público envolvido. No campo da neurociência, estudos mostraram que o engajamento é sempre o resultado de uma combinação de reconhecimento e surpresa. Muito reconhecimento leva ao tédio. Muita surpresa não permite que os espectadores se conectem, que entrem no seu mundo. Portanto, você precisa de um equilíbrio único dos dois elementos, o que também diferirá dependendo do contexto geral em que você situa seu trabalho. As artes clássicas geralmente provocam mais reconhecimento. As artes contemporâneas podem trabalhar mais explicitamente com o elemento de surpresa.

No processo de edição, você está editando principalmente o ritmo da peça. Para John Dewey, o ritmo é o princípio formal essencial na ciência e na arte. "Como o ritmo é um esquema universal da existência, subjacente a toda realização de ordem na mudança, permeia as artes, literárias, musicais, plásticas e arquitetônicas, assim como a dança." (DEWEY, 1934, p. 156). Dewey define ritmo como a 'variação ordenada de alterações' (Id, p. 160). O ritmo da arte, em certa medida, sempre copia tanto o ritmo do corpo humano (sua respiração, o pulso de sua circulação sanguínea, ...) quanto os ritmos da natureza; isso é no- 
vamente a 'oscilação entre dentro e fora'.

Dewey continua a enfatizar a importância da 'universalidade de intervalos nas obras de arte'. "Eles especificam e se relacionam ao mesmo tempo." (Id, p. 164). Quando, como dramaturgo, apoio o processo de edição de uma peça de dança, grande parte da minha atenção está focada nas transições entre as seções. Para alcançar uma variedade envolvente no ritmo da peça, toda transição requer uma solução única. É na não-batida, nas pausas, onde a qualidade única de um ritmo é definida. "Na ordenação rítmica, todo fechamento e pausa, como o resto em música, conecta assim como delimita e individualiza." (Id, p. 179).

Nas artes cênicas, os dois principais sentidos sendo abordados são o olho e o ouvido. O ritmo visual e o ritmo auditivo são trilhas separadas que ainda estão conectadas e se influenciam. "O olho é a sensação de distância. (...) Os sons vêm de fora do corpo, mas o som em si é próximo, íntimo. (...) Genericamente falando, o que é visto desperta emoções indiretamente, através da interpretação e da idéia associada. O som agita diretamente, como uma comoção do próprio organismo." (Id, pp. 246-247) Essa é uma das razões pelas quais o ritmo auditivo é sempre mais forte que o visual e porque a relação entre música e movimento é tão crucial. A música pode dar suporte, mas também matar o impacto visual.

Por fim, como Murch indica na citação acima, você também precisa orientar o foco de atenção do público. No palco, todo corpo é um centro de atenção. Mas, enquanto nas práticas tradicionais de teatro ocidental o centro das atenções sempre foi explícito, nas práticas contemporâneas existem frequentemente vários centros de atenção. Cunningham se recusou a ter um centro de foco claro e Anne Teresa De Keersmaeker explorou por um longo período em sua car- reira a forma elíptica, que sempre tem pelo menos dois centros iguais. No processo de edição, há modos de esclarecer e enquadrar os diferentes centros de atenção, para que o público os siga com você ou perceba que eles têm a liberdade de decidir por si mesmos.

\section{Conclusão: a dramaturgia como prática criativa e somática}

Mesmo em sua história profissional relativamente curta, a dramaturgia (da dança) tem sido associada principalmente ao componente racional e teórico do conhecimento: o 'olho externo', que à distância mantém uma visão geral e dá significado e coerência à prática corporificada dos que criam e fazem, dos artistas.

As práticas dramatúrgicas contemporâneas, no entanto, borram essa dicotomia. A 'amizade' criativa entre dramaturgo e coreógrafo pressupõe tanto promixidade e intimidade quanto distância. Já na função de testemunha, o 'olho externo' se torna um 'corpo externo' que brinca de maneira criativa variando sua distância do processo criativo e, ao fazê-lo, influencia o processo somática e energeticamente. Mesmo nas funções mais convencionais do parceiro de diálogo que escuta, e do editor que ajuda a moldar o ritmo, toda a fisicalidade do dramaturgo está envolvida.

\section{Bibliografia}

ADOLPHE, Jean-Marc (1997), La dramaturgie est une exercise de circulation pour tenir le monde a l'ecart, in: Nouvelles de Danse, Dossier Danse et Dramaturgie, nr. 31 (1997). Brussels: Contredanse. pp. 31-34. 
ALBRIGHT, Ann Cooper (1997), Choreographing Difference: The Body and Identity in Contemporary Dance. Middletown: Wesleyan University Press.

BARBA, Eugenio (1991), Dramaturgy, in: Barba, Eugenio and Savarese, Nicola (eds.): A Dictionary of Theatre Anthropology: The secret art of the performer. London, New York: Routledge, pp. 68-73.

BEHRNDT, Synne K. and Turner, Cathy (2008), Dramaturgy and Performance, Palgrave Macmillan.

BLEEKER, Maaike (2003), Dramaturgy as a mode of looking, in: Brizell, Cindy and Lepecki, André (eds.), On Dramaturgy, the labor of the Question. Women \& Performance: a journal of femininst theory. Vol. 13:2, Issue 26. New York: NYU. pp. 163-172.

CVEJIC, Bojana (2009), The lgnorant Dramaturg, in: Blok Suzy (ed.), Perspectives on Potential Dance Dramaturgies. Amsterdam: Dancemakers. pp. 22-33.

DEWEY, John (1934/2005), Art as EXperience. New York: Penguin Books, Perigee Paperback edition.

ETCHELLS, Tim (1999), Certain Fragments, Contemporary Performance and Forced Entertainment. London: Routledge.

FABIAO, Eleonora (2003), Dramaturging with Mabou Mines: Six proposals for Ecco Porco, in: Brizzell, Cindy and Lepecki, André (eds.), On Dramaturgy, the labor of the Question. Women \& Performance: a journal of femininst theory. Vol. 13:2, Issue 26. New York: NYU. pp. 29-40.
GRITZNER, KAROLINE, PRIMAVESI, PATRICK and ROMS, HEIKE (eds.) (2009), On Dramaturgy. Performance Research. Vol 14. No. 3., London: Routledge.

KUNST, Bojana (2009), The Economy of Proximity. Dramaturgical work in contemporary dance, in: Gritzner, Karoline, Primavesi, Patrick and Roms, Heike (eds.), On Dramaturgy. Performance Research. Vol 14. No. 3. London: Routledge. pp. 81-88.

LEPECKI, André (2010), Dramaturging, A quasi-objective gaze on anti-memory, in: Peeters, Jeroen (ed.), Are we here yet? Dijon: Les presses du réel. pp. 64-71.

LEPECKI, André and BRIZZELL, CINDY (2003), Introduction: The Labor of the Question is the (feminist) question of dramaturgy, in: Brizzell, Cindy and Lepecki, André (eds.), On Dramaturgy, the labor of the Question. Women \& Performance: a journal of femininst theory. Vol. 13:2, Issue 26. New York: NYU, pp. 15-16.

MASUCH, Bettina (2009), (no title), in: Peeters, Jeroen (ed.), Are we here yet? Dijon: Les presses du réel. pp. 136-137.

MONTAIGNAC, Katya (2013), Paradoxes of the Dance Dramaturg, in: Hansen, Phil (ed.), Dance and Movement Dramaturgy, Canadian Theatre Review, 155. Toronto: University of Toronto Press, pp. 10-15.

ONDAATJE, Michael (2002): The Conversations, Walter Murch and the Art of Editing Film. Toronto:

PEETERS, Jeroen (ed.) (2010), Are we here yet? Dijon: Les presses du réel. 
RADOSAVLJEVIC, Duska (2009), The Need to Keep Moving, Remarks on the place of a dramaturg in twenty-first century England, in: Gritzner, Karoline, Primavesi, Patrick and Roms, Heike (eds.), Performance Research, On Dramaturgy, Vol 14, No. 3. London: Routledge, pp. 45-51.

STALPAERT, Christel (2009), A Dramaturgy of the Body, in: Gritzner, Karoline \& Primavesi, Patrick \& Roms, Heike (eds.), Performance Research. On Dramaturgy, Vol 14, nr. 3. Abingdon: Routledge. pp. 121-125.

STALPAERT, Christel (2014), Becoming the Outside Body, Implicated in the Life of Others: Corporeal Dramaturgy and the Ethics of Instability / Sustainability, in: Pewny, Callens, Coppens (eds.), Dramaturgies in the New Millennium. Relationality, Performativity, and Potentiality. Theater Schriftenreihe. Gunter Narr Verlag.

STUART, Meg (2010), The Big Ear, in: Peeters, Jeroen (ed.), Are we here yet? Dijon: Les presses du réel. pp. 134-135.

TRENCSENYI, Katalin (2015), Dramaturgy in the Making. London: Bloomsbury.

KERKHOVEN, Marianne Van (1997), Le processus dramaturgique, in: Nouvelles de Danse, Dossier Danse et Dramaturgie, nr. 31. Brussels: Contredanse. pp. 18-25.

KERKHOVEN, Marianne Van (1994), Writing without a pencil in the hand, in: Van Kerkhoven, Marianne (ed.), Theaterschrift 5-6, On Dramaturgy. Brussels: Kaaitheater. pp. 140-148.
IMSCHOOT, Myriam Van (2003), Anxious Dramaturgy, in: Brizzell, Cindy and Lepecki, André (eds.), On Dramaturgy, the labor of the Question. Women \& Performance: a journal of femininst theory. Vol. 13:2, Issue 26. New York: NYU. pp. 57-68.

WILDSCHUTH, Liesbeth (2009), Reinforcement for the choreographer: The dance dramaturg as ally, in: Butterworth, Jo \& Wildschut, Liesbeth (eds.), Contemporary Choreography. A critical reader. Oxon: Routledge. pp. 383-398.

ZAPPEN, James P. (2004), The Rebirth of Dialogue. Bakhtin, Socrates, and the Rhetorical Tradition, New York: State University of New York Press.

ZIMMER, Jacob (2013), Friendship is no day job and other thoughts of a resident dance dramaturg, in: Hansen, Phil (ed.), Dance and Movement Dramaturgy, Canadian Theatre Review, 155. Toronto: University of Toronto Press. pp. 16-20.

Recebido: 28/08/2019

Aprovado: 29/11/2019 